\title{
Physicality in Postcolonialism: Tensions at the Asian Rural Institute
}

\author{
Samantha Senda-Cook* \\ Department of Communication Studies, Creighton University, Omaha, NE, United States
}

The Asian Rural Institute (ARI) is a transnational NGO that has a unique model of education and was founded in response to Japan's role as a colonizer. It invites participants from around the world to learn sustainable agriculture, servant leadership, and community advocacy at their campus in Tochigi, Japan. Postcolonial studies has a strong foundation of analyzing physical elements such as bodies and space and their role in both controlling colonized people and resisting colonizers. I argue that the complications of postcolonial and racial relationships manifest physically through movement and shared space at ARI, both of which operate as tensions that support (and sometimes undermine) selfdetermination and survivance, key characteristics of decolonization. This analysis

OPEN ACCESS

Edited by:

Kundai Chirindo, Lewis and Clark College, United States

Reviewed by: Shinsuke Eguchi, University of New Mexico, United States Ako Inuzuka, University of Pittsburgh at Johnstown, United States

*Correspondence: Samantha Senda-Cook SamanthaSenda-Cook@ creighton.edu

Specialty section: This article was submitted to Science and Environmental Communication, a section of the journal Frontiers in Communication

Received: 14 June 2021 Accepted: 11 August 2021 Published: 31 August 2021

Citation:

Senda-Cook S (2021) Physicality in Postcolonialism: Tensions at the Asian

Rural Institute.

Front. Commun. 6:725076. doi: $10.3389 /$ fcomm.2021.725076 contributes to postcolonial scholarship by providing another means of conceptualizing movement and linking space to consubstantiation.

Keywords: postcolonialism, bodies, space, rhetoric, movement

\section{INTRODUCTION}

"It is boring and hard, but we practice living together every day," said the director of the Asian Rural Institute (ARI) one day at Morning Gathering. She was referring to how people from all over the world who come from vastly different backgrounds try to do the hard, physical work of running a sustainable farm together. ARI is a transnational NGO that has a unique model of education and was born out of Japan's role as a colonizer. Like other Christians in Japan in the 1970s (Duró, 2020), the founder of ARI-Toshihiro Takami-sought to right some of the wrongs Japan perpetrated against its neighbors through colonization. Despite not discussing colonization explicitly in its training manual (2019), ARI still communicates its focus on marginalized community members, writing:

ARI's training is especially centered on serving marginalized peoples living in grassroot rural localities - with a focus on the landless, peasants, child laborers, street children, outcasts, refugees, war victims, the disabled, and those who are politically oppressed, economically deprived or who experience discrimination. (p. A-6)

The original focus of ARI was on other Asian countries because much of Japan's aggression had been perpetuated against them, but organizational leaders saw that people in countries outside of Asia had also been the victims of colonization and sought to expand their efforts. Now they accept participants from all over the world. This makes for a novel transnational NGO while also creating a space where people from different racial, religious, cultural, and economic backgrounds must work alongside each other in the same space daily.

The organization is rooted in Christianity, which comprises only $1.1 \%$ of the Japanese population (U.S. Department of State, 2019), and strives to provide education in the areas of sustainable agriculture, servant leadership, and community advocacy. Three types of workers keep ARI running. 
First, permanent staff are from a variety of countries: Japan, the United States, Ghana, the Philippines, and India when I was there; they are the fundraisers, farm and meal-planning experts, and office managers for ARI. Second, participants are there for education; in some ways, they are students, learning and perfecting their knowledge in critical areas, and in other ways, they are experts themselves. They are leaders in their own communities, selected because they have demonstrated their knowledge and desire to know more about the three focal areas. They are from countries that, through colonization, have been torn apart and formed anew by outsiders indifferent to indigenous cultural foundations (e.g., Sierra Leone, Cameroon, Indonesia, and the Philippines). The final group at ARI are volunteers, who are there to support the education process by working in the office, in the kitchen, and on the farm while participants are in class or on fieldtrips. They are generally from wealthy countries where being white carries great advantages (e.g., Japan, Germany, and the United States).

Importantly, staff, participants, and volunteers all work together to run a transnational NGO that houses residents, grows $90 \%$ of its own food, graduates classes of about 25 yearly, fundraises to support most of the participants, and maintains relationships with local food producers. I argue that the complications of postcolonial and racial relationships manifest physically through movement and shared space at the Asian Rural Institute. In this essay, I provide a review of postcolonial studies, focusing on how scholars have addressed physicality. Then, I describe my methodology, engaging in reflexivity about my own position at ARI, and provide background about Japan as a context for ARI's decolonizing efforts. While ARI is based in Japan and adheres to some Japanese cultural traditions, it actively rejects other aspects of Japanese society and adopts values from other global cultures. Next, I delve into my findings, explaining not only the tensions of movement and shared space but also how these two manifestations support (and sometimes undermine) self-determination and survivance, key characteristics of decolonization. Finally, I articulate my contributions to postcolonial literature by drawing a finer focus on physicality and its theoretical connections to indigenous struggles.

\section{POSTCOLONIALISM, BODIES, AND SPACE}

As a theoretical approach, postcolonialism emphasizes the extant structures that link historical colonizing practices with contemporary problems (Shome and Hegde, 2002). Tiara Na'puti (2020) explained, "postcolonial theory attends to questions about how cultures persist after colonization, the use/misuse of knowledges about colonized peoples, how formerly colonized and colonized peoples respond to systems of oppression, and the subjugation of colonized peoples' histories and epistemologies" (p. 8). I use the term to indicate that this research takes for granted the problems of colonialism and the connections to past wrongs enduring today. Additionally, I am especially interested in the resistance to such problematic structures in the form of decolonization, which is a branch of postcolonial research. This theoretical body of literature produces, in short, "a rich discussion of resistance, agency, and voice" (Dykstra-DeVette, 2018, p. 182). Such discussions are necessarily developed by considering the means by which power structures endure, degrade, and collapse such as through discourse as well as physical elements. As Na'puti (2020) emphasized, "Understanding the politics of colonialism requires an understanding of the places it reaches and the bodies of people that contest it and reproduce it" (p. 3). Postcolonial scholars have written extensively about physical elements like bodies and spaces and their relationships with power.

In conceptualizing how power is perpetuated through colonial legacies and contemporary forms of neocolonialism, scholars examine how bodies-their appearance, representation, and regulation-function rhetorically. In some cases, bodies come to stand in for the sovereignty of the nation or as a rationale for colonizing communities, which means that the bodies of individuals can take on particular significance (Hasian and Bialowas, 2009; Martin, 2018). In contemporary times, lingering colonial associations can manifest in how people read one another's bodies in colonized places such as Hawai'i (Christensen, 2020). Additionally, associations of sex, gender, sexuality, and race with colonized people's bodies become indicators of power and one of the means by which colonialists control people both in the past and present (Amos, 2017; Banerjee, 2012). For example, scholars have thoroughly analyzed the violence that Korean women endured under Japanese occupation and the cultural impact it had on not only individuals but also international relations between Korea and Japan even in contemporary times (Kwon, 2017; Park, 2014). Jeahwan Hyun (2019) contended that Japanese colonizers sought control through eugenics, writing that one theory at the time argued that "a mixture of biologically similar races would be eugenically superior to both original populations, and thus interracial marriage between Japanese and Koreans would benefit the Japanese Empire" (p. 494). However, people also deploy their bodies in acts of resistance (Enck-Wanzer, 2011). In one example, Stephen John Hartnett (2013) traced the ways that body rhetoric per se advanced political arguments in Tibet in the face of Chinese colonization. Like bodies, space is a productive vehicle for theorizing postcolonialism and physicality.

Historically, the link between colonization and space is clear. Colonists want resources, cheap labor, and strategic power; land is a way to attain and maintain those advantages, which means that controlling space ensures the oppression of indigenous people (Endres, 2009). ${ }^{1}$ Emphasizing the connection between the physical world and the political one, Kundai Chirindo (2018) articulated, "Colonization was a reconfiguring of space, time, and matter that turned African spaces into spheres of influence first,

\footnotetext{
${ }^{1}$ I recognize the differences between land, place, and space. Although postcolonial scholars use these three terms to mean different things at times, I am using them interchangeably in this paragraph because I am more concerned with physicality in general and space. The tension that I am discussing in this essay is about sharing space-only touching briefly on how some participants feel about ARI as a place. Land is one manifestation of space and that is relevant to farm work, but I also refer to indoor spaces such dorms and kitchens.
} 
then into nations" (p. 386). This is particularly significant because places and land itself are part of individual and collective identities (McCue-Enser, 2020; Na’puti, 2019). Japanese colonizers used space strategically not only for resources but also to control people (Nam, 2018). Lei Song (2021), for example, detailed how prison functioned towards these ends: "the panopticon surveillance [of Japanese guards] embedded in the Chiayi Prison [in Taiwan] served as a tool of physical oppression and mental domination" (p. 10). Controlling spaces and places-and the ways that people move through those spaces and who can and cannot be there-is not only a show of force. It also undercuts the cultural foundations of groups of people and compromises their identities. Shifting spaces and denying access to land-just as controlling other people's bodies does-ensures continued subjugation.

While this essay addresses bodies and space, it does so indirectly through the discussions of movement and shared space. Therefore, while concepts like the sexualization of bodies, portrayals of violence in media, the grounding of identity in place, and traces of diaspora through online communities have informed my understanding of postcolonial theories (Schwartz-DuPre, 2014), I engage them adjacently to get at the physical elements in a different way. The concept of shared space is not one that I would apply to colonial situations since the elements of power are so unbalanced. Concepts like conquering or occupying would more appropriately describe what is happening and the literature about space, place, and land addresses these. By contrast, the movement of bodies is a bit complicated when considered in the context of colonialism. On the one hand, there is privilege in movement for those who choose to move. When wealthy people choose to go to a place to "help," their movement is a sign of privilege. On the other hand, when people are compelled or forced to move because of violence, resource shortages, climate change, etc., the movement-even when theoretically voluntary-is not a privilege. Obviously, slavery and human trafficking-forced movement and forced labor-is oppression, not privilege. Although the movement of large groups of people-diaspora-might be a form of privilege if they have the means and desire to move, in the context of a new country, the movement disadvantages those who are recently resettled. Moreover, diaspora itself can reveal vast oppression in parts of the world where people have little choice but to move or face lethal consequences. This essay is not about diaspora, but it is important to note that scholars address this topic in depth (see, e.g., Corrigan, 2019; Drzewiecka, 2002; House, 2013). My essay contributes to postcolonial theory by making salient physical practices on a sustainable farm that reveal the complications of physical bodies and spaces interacting together in a transnational space shaped by colonization. Additionally, it focuses on attempts at decolonization to limn the consequences of such efforts.

\section{CONTEXTUALIZING ARI AS A RESEARCH SITE}

The field refers to both a physical and abstract site of research in this project. Therefore, in this section, I describe my methodology and Japan as a context for ARI's rhetoric. I adopted a field methods approach, which emphasizes understanding rhetoric in situ and speaking to people to access forms of rhetoric that would otherwise remain undocumented (Middleton, SendaCook, and Endres, 2011). Once a critic assembles artifacts (e.g., interview transcripts and field notes), they conduct a rhetorical analysis to discover how ideologies are bolstered or challenged, arguments are formed and defended, and material spaces shaped through discourse. I also incorporated postcolonial theory, which moves the critic beyond unnuanced methodologies that are, "not ... equipped to deconstruct the subtle mechanisms of Othering that structure the neocolonial discursive regimes of globalization" (Parameswaran, 2002, p. 312). Instead, this approach is, "sensitive to the careful positions one must construct in relation to representational politics" (Hanchey, 2016, p. 15). With this in mind, I obtained IRB approval and used participant observation and interviewing (45 people) to produce field notes and transcripts for rhetorical analysis. I also analyzed materials such as the ARI Training Manual. I volunteered at ARI for five months in 2019, averaging about $30 \mathrm{~h} /$ week.

Although ARI does not represent the Japanese government or even Japanese culture more broadly, ${ }^{2}$ it is located in Japan and begins its training for participants by recounting Japan as a colonial power. Therefore, it is important to discuss Japanese colonization as a contextual element of my analysis. One often undiscussed example of Japan's colonizing practices is of the Ainu people in Hokkaidō, which one interviewee at ARI mentioned. Acknowledging it here links, "the case of the Ainu into global conversations of Indigeneity" (Grunow et al., 2019, p. 599). Similar to other colonizers, Japan exercised power by controlling language (Pieper, 2019), disrupting traditional family structures (Liu, 2019), and meeting resistance with brutal force (Louzon, 2018). The horrors of colonization-both in Asian and Europe-have been well documented, but it would be a mistake to assume that the foundations for colonization were the same. As Jin-kyung Park (2014) argued, "ruler and ruled shared close racial, cultural and religious affinities and ... colonial medical power did not stem from white hegemony and Christian religious authority" (p.108). Although to outsiders, people from Asian countries would all be considered Asian, Japanese people have sought out "an alleged foreignness" as a justification of the superiority of some people over others (Amos, 2017, p. 577), which multiple Japanese staff members at ARI discussed openly.

Colonization and race were common topics at ARI. For example, one Japanese staff member discussed the first time she identified as Asian:

When I was in high school, Takami [the founder of ARI] came to my high school when I was 16 or $17 . .$. I saw men, Asian men came along with him and then that was my first time to see um Asian. But it's not Chinese,

${ }^{2}$ Staff would often mention how ARI is not Japan, marking the cultural differences between the campus and the surrounding country. Three different Japanese female community members lamented separately to me about having to leave campus at times and conform to typical Japanese gender expectations. 
Japanese, northeast Asian. They are Indian. I mean northeast Asia; we're northeast Asia: Japan, Korea, and then Chinese. We are similar Asians. But that was to see Indian, more black, dark brown faces. I knew on TV but first time to see them. And he talked about Asia, Asia, Asia. And I thought, ah! We are part of Asia. You are, that's right! And I didn't realize that.

This quote illustrates some of the nuances of race, nationality, and identity in Japanese society, and, significantly, how ARI challenges those by fostering feelings of shared identity among Asian people from different countries. In another example, the Director of ARI invited me to join the participants for their orientation so that I could understand the foundations of this NGO. She began by describing how the Japanese army had invaded many Southeast Asian countries and killed 20 million people, which drew participants' attention to colonization per se. In another instance, a Japanese staff member discussed Japan's invasion of Manchuria in his Morning Gathering presentation. Expanding out of Japan and marking ARI as transnational, participants and staff had many stories of conflict and colonization that they shared in interviews. As Ellen Gorsevski (2013) argued, "Religious, ethnic, and political conflict is a telltale marker of postcoloniality, posing great challenges for political leaders who must communicate with diverse, fractured audiences" (p. 175). Examples from their own lives include an entire community being displaced for an infrastructure project in the Philippines, fighting for independence and against colonial governments in India, learning how to use their recently-passed constitution to lobby the government for change in Kenya, fleeing violence in Sierra Leone and living in a refugee camp for years, and, in multiple countries, being dependent on foreign nations for imported food, which makes them food insecure at times. Historical and modern, talk of colonialism emerged spontaneously at times and helped contextualize community members' experiences. During these activities, I was aware of the similarities and differences between and among staff, volunteers, participants, and me.

Field methods demand self-reflexivity because a critic's body (e.g., skin color, age, weight, height, ability, sexuality, and gender) matters when interacting with people (Middleton, Hess, Endres, and SendaCook, 2015). As Charles E. Morris, (2014) defined, "Reflexivity is an unceasing process of self-engagement, deeply reading one's multiple cultural, political, ideological situatedness and its implications, privileges, relations to others, and effects" (p. 105). Not only does the critic's presence impact how other people interact with and read them, it also offers advantages and disadvantages depending on how well the critic fits in with a community (racially, ideologically, etc.) or whether or not they are interpreted as an academic professional, for example. I came into this research site in a position of power because I am a highly educated white person. While not quantitatively dominant in Japan or at ARI, being white offered me unearned privileges in many circumstances. Additionally, as a United States American who could speak conversational Japanese, I navigated most situations easily, was met with generosity and openness throughout Japan, and was able to get help when I needed it.

Since World War II, Japan and the United States have had a close relationship. The U.S. Department of State (2021) writes,
"The United States-Japan Alliance has served as the cornerstone of peace, security, and prosperity in the Indo-Pacific and across the world for over 6 decades" (n.p.). The block quote from the staff member above continues and illustrates this point:

Maybe many of our generation thought we were part of American rather than part of Asia. America seems more closer than other Asia countries, ne? ${ }^{3} \mathrm{Um}$, yeah. So much culture, and was the organization, TV, movies, everything is. But we don't see um Philipino movies, Philipino singers. Only Americans, Europeans on TV. Don't see Bangladesh or Indians on TV or anywhere. So, that was big shock for me. Ah! These are the Asian. Also I'm an Asian too.

Her personal experience of this relationship shaped the way that she saw herself and understood her own racial identity. The closeness of Japan and the United States is troubling to some Japanese people who worry about losing autonomy. For example, another staff member was critical of this relationship, explaining that Japan supported the United States war efforts with money but that lately (in 2019) that had not been enough. He said, "Now they need blood," and not only money, meaning that they might have had to send troops. While this unique relationship exists and was discussed occasionally at ARI, my being read as "white American" certainly offered advantages that might not have been extended to people of color from the United States and other countries.

Financially speaking, I was supported by a Fulbright grant, which enabled me to rent housing off-campus that was more expensive and afforded more privacy. This was at times a disadvantage because announcements would go out through the dorms if the schedule was changed, for example. Yet, overall, having space to myself and access to a kitchen were privileges that other volunteers and participants did not have. Moreover, I am a native English speaker, which is significant at ARI because English is the lingua franca. Most staff, volunteers, and participants spoke at least two languages (some spoke half a dozen or more). While not knowledgeable about or skilled at farming and animal husbandry, I am able-bodied, which meant that I could work alongside community members. This was invaluable for building relationships and observing daily life at ARI. These many privileges along with my status as a researcher and non-Christian made me an outsider at times but, more often than not, I was part of the community. These aspects all shaped my experience at ARI, how people interacted with me in the field and in interviews, and how I interpreted my data.

\section{POSTCOLONIAL TENSIONS OF MOVEMENT AND SHARED SPACE}

This case study illustrates the tensions present for one transnational NGO trying to combat decades of negative

\footnotetext{
${ }^{3}$ Adding "ne" to the end of a sentence is common at ARI. It functions as the equivalent of saying, "you know" or "right" at the end of a sentence in English. In Japanese, the phrase is "desu ne," but ARI has adopted its own version.
} 
impacts from colonization. Toshihiro Takashi, ARI's founder, "was ... born into a colonial world marked by the ideology of Japanese colonialism that understood the Japanese as being a superior "race"” (Gardner, 2017, p. 26). After meeting people who were colonized under Japanese rule, he began to question the patriotic rhetoric that justified Japanese rule and later in life sought a means of repairing the damage wrought through colonization. From its infancy ARI focused on teaching subsistence farming to people as a way to: 1 ) ensure that they always had enough to eat, 2) empower them to resist neocolonial practices that often result in them losing their land, and 3) building stronger communities through the sharing of food. Through classes and informal discussion, many staff members and some participants directly discussed maintaining one's power in the form of land. For example, one farmer in class talked openly about how indigenous people lose their land because they go into debt trying to convert to industrial farming. In its current form, ARI underscores the importance of the physical world to postcolonial thinking through two tensions: movement and shared space. Using bodies and space rhetorically, ARI manages to subtly impart lessons and values while privileging equality for participants and volunteers to internalize. Moreover, these two themes illustrate two key concepts of deconolonization: self-determination and survivance.

\section{Movement}

There is power in movement, made clear by the pattern of the movement of colonization regardless of the form it takes (e.g., resource-extraction, forced labor, religious conversion, social and environmental programs, and pop cultural imperialism). In general, wealthy people travel to "less fortunate" regions of the world to "create jobs," "educate," "help," and "spread the good word." While these efforts almost certainly do help people in some circumstances, they also have clear underlying assumptions about who has the knowledge and means to positively impact a place. ${ }^{4}$ Although this pattern of privilege may be evidence of a rhetorical mindset of conquest and epistemology, equally the reversal of this pattern can be rhetorical itself for its capacity to (re)shape the efforts of NGOs. In this case, there are still some assumptions about knowledge and means but instead of sending people from wealthy countries. ${ }^{5}$ somewhere else to teach residents about sustainable agriculture, community advocacy, and servant leadership, ARI brings Black and Asian people

${ }^{4}$ It is worth noting that this pattern does not hold all the time. For example, in bringing West African people to the United States as slaves performing physical labor, European Americans were also intentionally bringing West African expertise in plants, farming, and cooking. Harris, J (2012). High on the Hog: A Culinary Journey from Africa to America. New York: Bloomsbury Publishing.

${ }^{5}$ In the United States, the people traveling abroad in these volunteer efforts are often white. At ARI, the people from the United States were not uniformly white but rather represented multiple racial categories including white, Black, Asian, and Latinx. Additionally, most of the people I interviewed at ARI who had traveled to other countries for volunteer work were Asian. Therefore, even while patterns of colonization where largely enacted by white people, I am not comfortable characterizing the pattern of volunteering as a white phenomenon. My data do not support that in this case study. from less wealthy countries to Japan to learn those things. Although this could be interpreted as equally disempowering, given the colonial practices of forced labor and movement that the Japanese implemented, in this case such movement extends the privilege to a wider group of people and recognizes their extant knowledge, experience, and leadership.

This approach has distinct advantages; participants can be advocates for themselves, they know their land and communities best and know what will work, ARI can avoid colonial and missionary forms of interaction where an expert comes into an unknown area with unknown people to "help," participants also create productive relationships with one another and see other examples of people and organizations doing positive advocacy work. Moreover, they accumulate cultural cache in their home communities from having attended an education program in another country. Efforts like this can encourage smart, motivated people to give back to their home communities rather than seek opportunities abroad. As one staff member from Ghana critiqued, "And that is why many of the young people after graduation they want to go overseas. They want to go overseas, you know. Because the, the, the leaders have not created the opportunity for them to put what they have learned into practice." ARI's program invests in those home communities by supporting residents directly rather than sending a privileged outsider there, and participants appreciate this. One staff member-who is also a graduate of the program-described his own feelings when he was hired to work at ARI in animal husbandry:

Then it was very happy because ... Whoa! That is my job as veterinarian, ne. So, I was very happy to come. Not only to know that there is more ... what is this ... exciting part of the world. Because here, most of the, of my students are indigenous peoples. And I have been working with indigenous, different indigenous peoples, different tribal groups in the Philippines. That's also an exciting part. From India, from Africa, from Nepal, from ... And they say I am a tribal community; I belong to tribe of ... You see? Also, the same, also, as the people I'm working with in the Philippines. So, those things. And then here, it encompasses the community also. I belong to a community in the Philippines.

As this quote indicates, participants have a deep attachment to the land in their home countries; they want to preserve it for themselves and their children. Moreover, they are highly motivated to stay in their home communities once they return and be positive forces there. To facilitate this, each year, ARI hires one graduate of the program to return to be an exemplar for participants, someone who can look after their well-being and help them translate what they are learning to the situations in their home countries. Additionally, participants also share their knowledge. For example, one participant was discussing elephants as a pest in their gardens. Since this is not a problem in Japan, other participants jumped in with their suggestions about how to deter them. Such a sharing of knowledge is possible because ARI's structure supports 
participants from multiple countries learning advanced techniques together.

I contend that this reversal of the pattern of movement emphasizes self-determination because it offers participants the chance to choose what is right for them and their community. Na'puti (2020) summarized, "As one of the elements of the process and broader project of decolonization, selfdetermination is an internationally recognized mechanism of recourse for determining the legitimacy of control of particular populations and geographic locations" (p. 25). In situations of colonization and neocolonization, the capacity for controlling one's own body, land, food supply, etc. is compromised; the choices are limited. A participant from Sierra Leone joined ARI, "to strengthen our communities, to actually improve on a food self-sufficiency because, after the 11 years of civil war in our country, we faced a lot of challenges. Trouble, much hunger, and abject poverty and most of the communities are actually deprived and a lot of devastation caused by the rebels in our country." Asian Rural Institute (2019) recognizes this explicitly, writing, "Food sovereignty is the right of peoples to healthy and culturally appropriate food produced through ecologically sound and sustainable methods, and their right to define their own food and agricultural systems" (p. A-6).

Under a typical NGO model, people from wealthy countries are exercising their control and choice when they travel, help, or harm. But in this case study, participants can choose to come to ARI (or not as was the case in 2020 when concerns about COVID-19 led many participants to back out of their plans to go to ARI) and prioritize their own experiences. A Cameroonian participant described her motivation this way, "I'm here to learn both theory and practice, acquire skills to get more useful. That's to make myself more useful, back home, for my community." Another participant from Uganda came to learn how to increase yields from "a small piece of land." One of ARI's main recruitment methods is word-of-mouth among community members in their home countries, which would be unsuccessful if participants felt disenfranchised. One participant explained that after meeting with a graduate of the program in his community in Myanmar, he researched more about ARI because he is from a rural community and ARI centers rural life. He said, "Yeah, first thing I get to know from internet about ARI is that ARI is helping people from rural community, yeah. ARI trains people from different countries. That is what I'm interested." After talking with two graduates of the program, one Kenyan participant decided to focus on culture and politics; he said, "And so far, I'm based on issues of community development, I really like to mingle with others, and share things so that I may empower myself. ... So that I can help my community." After 9 months, they return to their home communities and decide whether and to what extent they incorporate their training from ARI. Many start planning what they will do just a few months into the program. For example, a Filipino participant explained, "When I'm home and I go back home, I will apply that to the three learning sites that we are building and coming here in ARI and bringing back the technology will be a big showcase to the learning site." Although these examples illustrate the participants' choice in coming to and learning at ARI, this element of self-determination has another side to it.

Movement is a tension in my analysis and not simply a good thing. Although ARI participants are taken care of to ensure that they have all of their needs met while in Japan, their selfdetermined movement is limited. First, they have limited resources in an expensive country. It would be difficult for most (but not all) participants to pay for a trip to different parts of Japan. Keeping this in mind, ARI organizes multiple trips around Japan for participants-and not volunteers-where they travel extensively (about 30 days of the 9 months) but as part of the group. Additionally, ARI staff will meet participants at the airport in Tokyo but do not do the same for volunteers; volunteers must pay for and navigate their way to ARI on their own. While these things can certainly be seen as conveniences, another interpretation might be that they are constrictions. Participants can choose to go into town and take short train trips to within about an hour of ARI (and ARI provides a map of the surrounding town and location of the train station in the Training Manual), but to travel further, they need to request permission. "Disappearance from the ARI campus," is "considered unacceptable and would not be permitted" (Asian Rural Institute, 2019, p. C-4). The issue, according to some members of ARI's staff, is that some participants in the past have been taken advantage of or involved in illegal activity. For example, one white U.S. American staff member explained that some participants have:

exploit[ed] the opportunity for us to essentially pay for them to come to Japan and do that. It's been an issue we've had in the past 15 years; we've had far too many people doing that. And by "far too many," I mean less than five, but more than three. So, around four. Four or five, I can't remember exactly.

He went on to describe how some people try to exploit others Visà-Vis ARI:

So, what ends up happening in a lot of these cases, especially in Africa, is they have what are called "brokers." So, these are people that they owe debt to or for whatever reason they have power over them. And they say, "here's an opportunity, let's send you to Japan to this program. You're going to pay back your debts because that's a rich country." And you gotta.

By this way of thinking, because ARI provides scholarships for almost every participant, this is an attractive opportunity for those who want to exploit it. Another white U.S. American staff member explained that this policy of granting permission, "is for [the participants'] protection.” They justify this by recalling past experiences in which what seemed like friendly meetings turned into someone trying to involve participants in illegal activities. Nevertheless, this protectionist rhetoric has been used to control people's bodies throughout history. Through their intentional inversion of the typical colonialist model of movement and their restriction of movement within Japan, 
ARI rhetorically reflects the complications a transnational organization faces when situated in network of past and present colonization. Although they are trying to create a better world, they feel they must still take a paternalist position and limit participants' movement; and in the process limit the participants' control and choice.

\section{SHARED SPACE}

The second tension in terms of physicality and postcolonialism at ARI involves shared space-and by extension shared labor-for the purposes of relationship-building and education. In my interviews, participants mentioned again and again how impressed they were that the director of the organization was working in the kitchen, the bathrooms, and the pig pen, as those are viewed as some of the most demeaning jobs and dirtiest spaces. One Filipino participant described her skepticism prior to coming: "I had little bit doubt when [the interviewer was] asking me whether I can clean these toilets, kitchen. I said, "I can do that." He told me, "Even our director is doing. Can you do that?" Actually, I didn't believe, fully.” Another participant expressed amazement:

The first time I saw it I was like, "Oh my God. What am I seeing?” These people don't just pick or teach, they do what they say. Many people always say things which they don't do. Learning by doing. They do what they say, washing dishes, cooking, cleaning, picking eggs, the pig pen. The director, I was like, "Wow, not in Cameroon."

Participants, volunteers, and staff-regardless of race, age, and sex-are in every working space on campus and expected to do every kind of work, including dirty work such as cleaning toilets and "women's work" such as making food. Another Cameroonian participant noted, "Everybody here is equal.... Now I come to ARI and I actually see how it's actually the director washes my plate. That really, really, really touched me." This reinforces the idea of servant leadership; as one Ugandan participant said, "I'm seeing the director, I'm seeing staff and upper management also participating in all activities of ARI, it is something I see, so this is also part of good servant leadership." In this way, no space was seen as "less than," no one was above doing a certain chore. Another participant from Sierra Leone made a similar connection: "When I came, I saw that leadership at ARI, training is practical. I saw the director and all other staffs coming working, serving as servants, workings together with participants. It was very impressive to me. I was very excited in such a leadership system I saw."

ARI also shares space racially through intentional hiring. No one discussed this directly, it was something that I noticed as a participant observer. Although most of the office staff were either Japanese or white U.S. Americans, the leaders of the crews that volunteers and participants worked with daily (i.e., produce farming, animal husbandry, and food preparation) were from Japan, India, the Philippines, and Ghana. Put another way, the people from whom participants learned and volunteers followed were all people of color. This ensures that power as well as space is shared among people of different races. Significantly, it models a productive, inclusive work environment for participants and volunteers because the leaders reflect the global, diverse world that ARI seeks to engage.

These forms of shared space create opportunities for developing shared identities and reconciliation. One Indian participant noted, "This working culture is really good. Even from this director to everyone is treated equally, and everybody working the same thing." A Filipino participant explained the system she is accustomed to:

If you have a higher place, you don't work so much. You just sit and look at people and "Uh, OK, how's everything?" And other people are doing the dirty work for you and you get all the credit for it. And also, in here everyone is part of a group. It's like you know you belong somewhere.

The end of this quote emphasizes one consequence of shared space, which is a sense of community, of belonging. This helps when conflicts inevitably arise. Several staff members discussed how people from countries or regions that have been or are currently at odds with one another will come to ARI and need to work together. When racism or sexism or religious conflicts occur, people still must work together to weed a field or turn the floor of a chicken coop. Then, later, they will need to eat in the same space and wake up to do exercises at 6:30 a.m. while looking at each other across a big circle. All of this contact makes it difficult to hold a grudge and continue a conflict. One German volunteer explained how she had become used to it: "When people started talking about ARI is a family, we are so close friends, I was like, OK. Sounds a little bit strange to me but now I just feeling comfortable around many people if it's not too long." To be sure, tempers flare and jealousies arise, frustrations leak out and, even sometimes for weeks, people are angry. But eventually, they will set their anger aside or talk to the person or come to some unspoken agreement because avoiding the person is not an option.

Along with the principles of sustainable farming, which participants can use to become more food secure and selfsufficient, through shared space they learn community building and servant leadership. These three principles help participants establish survivance, which, "indicates more than basic physical survival” (Na'puti, 2020, p. 26). Growing one's own food may fulfill a basic need, but community development and servant leadership help ensure that the traditions and stories of indigenous cultures continue, which is a key principle of survivance. One staff member who had graduated from the program several years before detailed his dissatisfaction with his own efforts to help his community in Ghana before coming to ARI. He was selling chemical fertilizers and pesticides, thinking that they would increase the yield of farmers and thus help feed people through the difficult dry season. However, he intimated:

That is one of the things that I always regret to involve myself in that job. Because people are dying, and people don't know how to apply the chemicals [safely]. And people are getting lots of diseases. That was one of the 
main reasons that led me to come here in 2001. I stopped selling the chemicals and looking for the best way of helping the farmers. And that's when somebody, one of the pastors, introduced ARI to me. That maybe this is where you get your answer to your question. And I was still, maybe they will let me come to the ARI.

Also, ARI addresses this directly in the Training Manual (2019): "Self-sufficiency is protection against the instability of monoculture, the exploitation of globalization's changing markets, and a tendency to take control over land, undermining local culture" (p. A-7). Sharing space can contribute to decolonization efforts by modeling the best practices of farming and leadership, ways to be self-sufficient; working alongside one another helps build community and create opportunities to learn from the staff as well as each other. Seeing and hearing from community leaders in other countries that have experienced the violence of colonization can be empowering, which is at the core of survivance.

Sharing space also means that ARI begins to feel like home for many people. After just a month or two of living there, two participants said explicitly that ARI was their second home. Furthermore, multiple expressed that they wanted to bring what they see at ARI to their own communities. One Cameroonian participant's words exemplify this idea:

I love the way ARI is organized in terms of work. Let me explain. The fact that we have everybody working in ARI, including the director, that's something amazing I've never seen. The fact that everybody knows what he [or she] has to do and does it, that's something I like the most. I want to go back to my community and build something like this. Yes. I want to build something where we all work together. Even if you are the boss, you do it. We work together. Because working together make the movement. We progress towards something.

Since staff, participants, and volunteers do all the different jobs, that means a conflation of home and work; any boundaries that existed between the two collapse. So, while cleaning the toilets and raking leaves build relationships, they also reinscribe the place as home. These are jobs that at other organizations would be fulfilled by hired workers. But this is a bit of Japanese culture coming in, as a Japanese staff member noted, because it is not uncommon for Japanese people to clean their workplaces, schools, and public spaces together to show their care and community. The fact that everyone at ARI all must clean together at 6:30 in the morning means that jobs are distributed equitably. It also ensures that, as one white U.S. American staff member put it, ARI is more than work, it is a lifestyle.

However, again, this is a tension with downsides of its own. For those who live in the dorms (volunteers and participants) very little private space exists. As mentioned, work begins at 6:30 am and work/life boundaries blur constantly. Furthermore, internet is restricted to one public building, meaning that what might usually be private conversations must happen in public spaces. Many community members expressed frustration at the lack of space. One German volunteer remarked, "Because for me,
I feel like, it's my right to have my own space, my own time, and in here, since you belong to a community, if you want some moment of silence alone, people reject always say, "Are you OK? Is something wrong?"” A Filipino participant said simply, "You can't have personal space."

While too much shared space aligns with the core of this tension, there is another side to it that may not be visible to all community members: Not all spaces are open to everyone. Predictably, the dorms are sex-segregated, which is to be expected at a Christian organization, especially where people of all different ages, cultures, and life experiences are intermingling. This makes it difficult for casual hanging out to happen between the sexes unless they are in a public space and is part of the point. Near the end of my time there, six U.S. American college students of different races came as volunteers and really changed the culture of the place by sitting exclusively with one another at lunch and pushing back against the rules. They were only there for about 6 weeks and struggled to fit in. One day, one of them asked me if I was coming to the volunteer party of if I was "being responsible." I said I did not know about it and asked where it was. They were going to hang out in the men's dorm. If they had gone through with it, I think they would all have been sent home early, but they decided to go camping instead. The privilege of having an option like this is not available to everyone at ARI, as I noted above with regard to movement.

More significantly, some spaces are locked, and others are not. For example, the dining room and classroom, which are next to the dorms and where the internet is, were locked every night. At a certain time, they shoo people to their dorms for the night so they can lock up. Additionally, they are really the only spaces outside of their dorms where participants and volunteers can talk or read or practice an instrument. By contrast, adjacent to (but technically offcampus), ARI uses a building-the seminar house-that is owned by another partner organization that is never locked. I did not know about it at first because it is not part of the unified campus. One morning, when I came up early to do some work online (there was no internet access in the place I rented for the first few months) and found the doors locked, a staff member told me I could use the seminar house, which was never locked. This is the building where groups of day-long or week-long Japanese volunteers would stay. It is further from the dorms and probably not in people's minds as a place to go to hang out, even though they could in theory. That this internet-available space is unlocked day and night draws attention to the spaces that are locked and prompts questions about who knows about this area and who does not. Yet, by and large, the sharing of space functions rhetorically to create feelings of equity among staff, participants, and volunteers. By developing an education model that disrupts the patterns of colonization present in some contemporary NGOs, ARI deploys physicality as a countermeasure to neocolonialism.

\section{IMPLICATIONS}

Postcolonial studies is ripe for full engagement with physicality because of the firm foundations established through theories of bodies and space. By controlling bodies and space, colonizers secured power and advancements that continue to give them 
advantages even in contemporary times. Colonization, bodies, and space are deeply embedded in one another; when colonizers reshape land, they also affect people's bodies (Fedman, 2018). In a poignant example, Sakura Christmas (2019) demonstrated how a push to produce soybeans in Manchukuo under Japanese imperialism produced negative environmental results and disease in the bodies of residents in the area. In this example, "ecological imperialism" not only yielded fatal results for some local people but also made salient the different conceptualizations of land that nomadic and agrarian societies held (p. 809). My argument builds on this literature to contend that ARI challenges these practices physically by encouraging different uses of bodies and understandings of space, but they are not perfect in their efforts and some of the physical practices reinforce racism by restricting participants' movements and only leaving a relatively unknown space unlocked. Despite this, Asian Rural Institute (2019) strives to, "empower and help [participants] reach their highest potential” (p. A-6). Through this case study, this essay contributes to postcolonial conversations in particular by emphasizing the ways that bodies moving (or not moving) through space communicate power and the processes by which sharing space-as opposed to taking and losing space-creates circumstances for physical as well as metaphorical consubstantiation.

Postcolonial scholars' focus on bodies and the means by which they are controlled thoroughly demonstrates how power is maintained and challenged. For example, Kevin D. Kuswa and Kevin J. Ayotte Kuswa and Ayotte (2014) explained the lengths to which some people must go to assert the last bit of power they have: "contemporary self-immolations often convey the desperate cries of individuals reacting against unconscionable oppression through one of their last available means of expression, burning their own bodies" (p. 108). My analysis illuminates another component of this, which is the power and privilege of movement. Moving allows different experiences and an accumulation of knowledge. Diasporic studies is one way that analyses of movement in postcolonial studies manifests, and these projects reveal strong place attachment and cultural traditions that are compromised through movement. Despite the persistence of memories in bodies and museums (Johnson and Pettiway, 2017), diaspora has meant for large groups of people a lack of recognition of their own intellectual traditions (Corrigan, 2019) as well as loss of family connections and personal historical knowledge (Drzewiecka, 2002). This case study gives postcolonial scholars another way to conceptualize the rhetorical function of movement, as an extension of power and choice. When understood as a physical element of an independent body, movement situates a person or group of people as worldly and wise. They are sought out for their expertise and hold revered status in the new places they go. By reversing the conventional pattern of global movement, Asian Rural Institute (2019) emphasizes that "all labor has dignity and equal value. Even though one may be formally educated, that person's labor and physical work is as valuable as any other work" (p. A-7). What is more is that movement in this case is an extension of a physical body and an indicator of self-determination, a key characteristic of decolonization.
Controlling space creates power for people on international as well as local scales. Postcolonial scholars have shown how the physical control of space maintains power; this study shows how shared space can communicate equality and how restricting access to spaces can also create inequality. People can see themselves as more similar as their bodies reflect the shared activities, food, and temperaments that accompany shared space. In this way, consubstantiality can develop. Through the sharing of space, labor, and food, two people can begin to understand their identities as created through one another (Burke, 1969). While Kenneth Burke conceptualizes this in a figurative way, I posit that postcolonial scholars could productively extend theories of space to recognize the role of physicality in consubstantiation. Shared space gives people the chance to see everyone working on the same job. They build identities together and develop themselves with the land itself, leading to consubstantiation. In a literal sense these practices ensure that their bodies become shaped by the same bending and lifting of shared labor and begin to be sustained by the shared food produced. Asian Rural Institute (2019) links these ideas together when they write, "Life of sharing is the sacrifice a living organism do or perform to support, protect, save and sustain the life of another" (p. A-5). Moreover, I suggest that scholars can deploy consubstantiation theoretically to enhance the concept of survivance because it strengthens ties between communities and reinforces relationships between different groups of people striving for independence, and between people and the lands they love so much.

Finally, it is worthwhile to connect my research to environmental communication scholarship directly. The relationship between colonization, bodies, and space makes postcolonial studies a natural fit for environmental communication research. And, indeed, pro-environmental practices-farming sustainably, using natural pesticides and fertilizers-are beneficial for marginalized people because they can retain more of their power through land ownership and community solidarity (Bullard, 1993; Christmas, 2019). Emphasizing this connection helps to unite two strong progressive movements: decolonization and environmentalism. ARI is one transnational organization that has taken on the project of connecting multiple forms of oppression and providing a model to stand against them. Challenging conventional global patterns of movement and persisting in shared space equally even when it is "boring and hard" does not mean ARI always has the right approach but represents a unique way of facing down postcolonial problems.

\section{DATA AVAILABILITY STATEMENT}

The datasets presented in this article are not readily available because the author collected the data for this study, and they are not available publicly. Requests to access the datasets should be directed to SamanthaSenda-Cook@creighton.edu.

\section{ETHICS STATEMENT}

This study involved human participants and was reviewed and approved by the Creighton University IRB-02 Social Behavioral 
committee. Written informed consent for participation was not required for this study.

\section{AUTHOR CONTRIBUTIONS}

The author confirms being the sole contributor of this work and has approved it for publication.

\section{REFERENCES}

Amos, T. D. (2017). The Subaltern Subject and Early Modern Taxonomies: Indianisation and Racialisation of the Japanese Outcaste. Asian Stud. Rev. 41 (4), 577-593. doi:10.1080/10357823.2017.1365816

Asian Rural Institute (2019). Training Handbook Tsukinokizawa, Tochigi: Asian Rural Institute.

Banerjee, S. (2012). Probing the Problematics of Gender and Sexuality: An Intercultural Approach to Critical Discourses on Body in the Colonial Bengali Magazine Nara-Naree. Glob. Media J. - Indian Edition 3 (1), 1-14.

Bullard, R. D. (1993). "Anatomy of Environmental Racism and the Environmental justice Movement," in Confronting Environmental Racism: Voices from the Grassroots. Editor R. D. Bullard (Boston: South End Press).

Burke, K. (1969). A Rhetoric of Motives. Los Angeles, CA: University of California Press.

Chirindo, K. (2018). Micronations and Postnational Rhetorics. Women's Stud. Commun. 41 (4), 383-393. doi:10.1080/07491409.2018.1551686

Christensen, P. (2020). Fake Meets Soul: Division Among Hawai'i's Japanese Surfers. J. Sport Soc. Issues 44 (5), 476-493. doi:10.1177/0193723519898704

Christmas, S. (2019). Japanese Imperialism and Environmental Disease on a Soy Frontier, 1890-1940. J. Asian Stud. 78 (4), 809-836. doi:10.1017/S0021911819000597

Corrigan, L. M. (2019). Decolonizing Philosophy and Rhetoric: Dispatches from the Undercommons. Philos. Rhetoric 52 (2), 163-188. doi:10.5325/ philrhet.52.2.0163

Drzewiecka, J. A. (2002). Reinventing and Contesting Identities in Constitutive Discourses: Between Diaspora and its Others. Commun. Q. 50 (1), 1-23. doi:10.1080/01463370209385643

Duró, Á. (2020). Historical Counter-narratives: Japanese Christians' Advocacy for South Korean Atomic Bomb Victims. Jpn. J. Religious Stud. 47 (2), 279-303. doi:10.18874/jjrs.47.2.2020.279-303

Dykstra-DeVette, T. A. (2018). Resettlement Rhetoric: Challenging Neoliberalism in Refugee Empowerment Initiatives. South. Commun. J. 83 (3), 179-191. doi:10.1080/1041794X.2018.1437925

Enck-Wanzer, D. (2011). Race, Coloniality, and Geo-Body Politics:The Gardenas Latin@ Vernacular Discourse. Environ. Commun. 5 (3), 363-371. doi:10.1080/ 17524032.2011.593535

Endres, D. (2009). The Rhetoric of Nuclear Colonialism: Rhetorical Exclusion of American Indian Arguments in the Yucca Mountain Nuclear Waste Siting Decision. Commun. Critical/Cultural Stud. 6 (1), 39-60. doi:10.1080/ 14791420802632103

Fedman, D. (2018). Wartime Forestry and the "Low Temperature Lifestyle" in Late Colonial Korea, 1937-1945. J. Asian Stud. 77 (2), 333-350. doi:10.1017/ S0021911817001371

Gardner, R. A. (2017). Asian Rural Institute: Living Together with the Earth. Euodoō: J. Rural Future Study 1, 24-46.

Gorsevski, E. W. (2013). Posting Notes on Buddhism: Aung San Suu Kyi’s Rhetoric of Postcolonial Subjectivity. J. Commun. Religion 36 (1), 173-195.

Grunow, T. R., Nakamura, F., Hirano, K., Ishihara, M., lewallen, a.-e., Lightfoot, S., et al. (2019). Hokkaidō 150: Settler Colonialism and Indigeneity in Modern Japan and beyond. Crit. Asian Stud. 51 (4), 597-636. doi:10.1080/14672715.2019.1665291

Hanchey, J. N. (2016). Agency beyond Agents: Aid Campaigns in Sub-saharan Africa and Collective Representations of Agency. Commun. Cult. Critique 9, 11-29. doi: $10.1111 / \mathrm{cccr} .12130$

Hartnett, S. J. (2013). “Tibet Is Burning”: Competing Rhetorics of Liberation, Occupation, Resistance, and Paralysis on the Roof of the World. Q. J. Speech 99 (3), 283-316. doi:10.1080/00335630.2013.806819

\section{FUNDING}

Funding for this project was provided by the Institute of International Education through a Fulbright Award to Japan in 2019 and through Creighton's Center for Undergraduate Research and Scholarship in 2020. The author would like to thank Kundai Chirindo, Shinsuke Eguchi, and Ako Inuzuka for helping to strengthen this essay. Additionally, thanks to Sol Kim and Sarah Tooley for their assistance.

Hasian, M., Jr., and Bialowas, A. (2009). Gendered Nationalism, the Colonial Narrative, and the Rhetorical Significance of theMother IndiaControversy. Commun. Q. 57 (4), 469-486. doi:10.1080/01463370903320849

House, C. A. (2013). Religious Rhetoric(s) of the African Diaspora: Using Oral History to Study HIV/AIDS, Community, and Rhetorical Interventions. Int. J. Commun. 7, 2027-2045.

Hyun, J. (2019). Racializing Chōsenjin: Science and Biological Speculations in Colonial Korea. East Asian Sci. Technol. Soc. Int. J. 13, 489-510. doi:10.1215/ 18752160-8005053

Johnson, M. A., and Pettiway, K. M. (2017). Visual Expressions of Black Identity: African American and African Museum Websites. J. Commun. 67, 350-377. doi: $10.1111 /$ jcom. 12298

Kuswa, K. D., and Ayotte, K. J. (2014). "Wor(l)ds on Fire: Postcolonial Rhetorics of Violence," in Communicating Colonialism: Readings on Postcolonial Theory(s) and Communication. Editors R. L. Schwartz-DuPre (New York: Peter Lang), 104-127.

Hyunji Kwon, H. (2017). The Paintings of Korean Comfort Woman Duk-Kyung Kang: Postcolonial and Decolonial Aesthetics for Colonized Bodies. Feminist Stud. 43 (3), 571-609. doi:10.15767/feministstudies.43.3.0571

Liu, Y.-C. (2019). Establishing Children's Legal Rights: Children, Family, and the State in Taiwan under Japanese Colonial Rule (1895-1945). J. Fam. Hist. 44 (3), 297-312. doi:10.1177/0363199019842591

Louzon, V. (2018). From Japanese Soldiers to Chinese Rebels: Colonial Hegemony, War Experience, and Spontaneous Remobilization during the 1947 Taiwanese Rebellion. J. Asian Stud. 77 (1), 161-179. doi:10.1017/S0021911817001279

Martin, P. (2018). Race, Colonial History and National Identity: Resident Evil 5 as a Japanese Game. Games Cult. 13 (6), 568-586. doi:10.1177/1555412016631648

McCue-Enser, M. (2020). Genocide in the Sculpture Garden and Talking Back to Settler Colonialism. Q. J. Speech 106 (2), 179-204. doi:10.1080/ 00335630.2020 .1744181

Middleton, M. K., Senda-Cook, S., and Endres, D. (2011). Articulating Rhetorical Field Methods: Challenges and Tensions. West. J. Commun. 75, 386-406. doi:10.1177/153270861665582110.1080/10570314.2011.586969

Middleton, M. K., Hess, A., Endres, D., and Senda-Cook, S. (2015). Participatory Critical Rhetoric: Theoretical And Methodological Foundations for Studying Rhetoric in Situ. Lanham, MD: Lexington Press.

Morris, C. E., III. (2014). Performing/rhetorical Studies: Differential Belonging across Intradisciplinary Borders. Text Perform. Q. 34 (1), 104-107. doi:10.1080/ 10462937.2013.849813

Na'puti, T. R. (2019). Speaking of Indigeneity: Navigating Genealogies against Erasure and \#RhetoricSoWhite. Q. J. Speech 105 (4), 495-501. doi:10.1080/ 00335630.2019 .1669895

Na'puti, T. R. (2020). "Rhetorical Contexts of Colonization and Decolonization," in Oxford Research Encyclopedia of Communication. Editor J. F. Nussbaum (Oxford: Oxford University Press). online. doi:10.1093/acrefore/ 9780190228613.013.156

Nam, P. S. (2018). The Immiseration of the Korean Farmer during the Japanese Colonial Period. J. Agrar Change 18, 281-298. doi:10.1111/joac.12202

Parameswaran, R. (2002). Local Culture in Global Media: Excavating Colonial and Material Discourses in National Geographic. Commun. Theor. 12, 287-315. doi:10.1111/j.1468-2885.2002.tb00271.x

Park, J.-k. (2014). Picturing Empire and Illness. Cult. Stud. 28 (1), 108-141. doi:10.1080/09502386.2013.775319

Pieper, D. (2019). The Making of a Foreign National Language: Language Politics and the Impasse between Assimilationists and Language Nationalists in Colonial Korea. J. Korean Stud. 24 (1), 63-95. doi:10.1215/21581665-7258055 
R. L. Schwartz-DuPre (2014). Communicating Colonialism: Readings on Postcolonial Theory(s) and Communication (New York: Peter Lang).

Shome, R., and Hegde, R. S. (2002). Postcolonial Approaches to Communication: Charting the Terrain, Engaging the Intersections. Commun. Theor. 12 (3), 249-270. doi:10.1111/j.1468-2885.2002.tb00269.x

Song, L. (2021). Panoptic Apparatus: A Study of the Japanese-built Prisons in Colonial Taiwan (1895-1945). J. Asian Archit. Build. Eng., 1-18. doi:10.1080/ 13467581.2021.1941984

U.S. Department of State (2019). 2019 Report on International Religious freedom: Japan. Office of International Religious Freedom. Available at: https://www. state.gov/reports/2019-report-on-international-religious-freedom/japan/ (Accessed July 31, 2021).

U.S. Department of State (2021). Reaffirming the Unbreakable U.S.-Japan alliance: Fact Sheet. Office Of the Spokesperson. Available at: https://www. state.gov/reaffirming-the-unbreakable-u-s-japan-alliance/ (Accessed July 31, 2021).
Conflict of Interest: The author declares that the research was conducted in the absence of any commercial or financial relationships that could be construed as a potential conflict of interest.

Publisher's Note: All claims expressed in this article are solely those of the authors and do not necessarily represent those of their affiliated organizations, or those of the publisher, the editors and the reviewers. Any product that may be evaluated in this article, or claim that may be made by its manufacturer, is not guaranteed or endorsed by the publisher.

Copyright $\odot 2021$ Senda-Cook. This is an open-access article distributed under the terms of the Creative Commons Attribution License (CC BY). The use, distribution or reproduction in other forums is permitted, provided the original author(s) and the copyright owner(s) are credited and that the original publication in this journal is cited, in accordance with accepted academic practice. No use, distribution or reproduction is permitted which does not comply with these terms. 